\title{
House-dust mite species in Bloemfontein, South Africa
}

\author{
Werner Sinclair, Louise Coetzee, Gina Joubert
}

House-dust mites (HDMs) are an important source of allergens that are reputed to act as a trigger for atopic disease. Climatic conditions in parts of South Africa are not suitable for their proliferation, and there is doubt whether they occur on the Highveld. We studied whether HDMs occur in homes in Bloemfontein, Free State.

Methods. Ten houses were sampled over a 1-year period. Dust was collected monthly or quarterly from a mattress, a bedroom floor and the living room floor of each house and examined for the presence of HDMs. Climate data were collected during the same period and a questionnaire was completed by home-owners to gather data on indoor factors that could influence mite proliferation.

Results. HDMs were regularly found in 3 houses (30\%).

Dermatophagoides farinae was the dominant species (97.5\%).
The highest numbers were found in winter, when climatic conditions were the least favourable. Climatic conditions never met the requirements for active proliferation of the mites. Indoor factors that may have promoted mite proliferation in some houses were artificial heating (especially under-floor heating), en-suite bathrooms and lack of adequate ventilation during the winter months.

Conclusion. HDMs do occur in central South Africa, owing to a microclimate created indoors. Adequate ventilation, to reduce indoor humidity, should suffice to reduce mite numbers and prevent atopic symptoms induced by them.

S Afr Med J 2010; 100: 164-167.
Mites (Arachnida, Acari) are an important source of allergens in house dust. ${ }^{1-3}$ Sensitisation to house-dust mites (HDMs) is thought to be a major risk factor for asthma, allergic rhinitis and atopic dermatitis. Much time and money are spent on prophylactic measures to reduce environmental levels of these allergens, often with limited success. These atopic individuals often have positive skin tests and radio-immunoassay tests (RASTs) to HDMs. While pointing to allergic sensitisation to the mites and their allergens, positive test results are only of practical value if the mites and allergens occur in the environment in which the patient lives.

More humid areas of the world carry higher concentrations of these mites in households, while mites and their allergens are reduced in more arid, colder regions. ${ }^{4}$ Bloemfontein is situated on the central plateau of South Africa, $29^{\circ} 06^{\prime} \mathrm{S} 26^{\circ} 18^{\prime}$ E, $1351 \mathrm{~m}$ above sea level and $421 \mathrm{~km}$ from the Indian Ocean. It has very cold, dry winters with low relative humidity and hot summers, with an average summer rainfall of $559 \mathrm{~mm}$ per year. Climatic factors in Bloemfontein ${ }^{5}$ would usually be seen as unfavourable for the proliferation of HDMs, and there is doubt whether they occur in significant numbers there. HDM allergens were found in $100 \%$ of households in the Edenvale area of Gauteng, reaching levels deemed to be unsafe in $20 \%$ of houses. ${ }^{6}$ Considerable seasonal variation could not be explained.

Department of Dermatology, Faculty of Health Sciences, University of the Free State, Bloemfontein

Werner Sinclair, MMed (Derm)

Department of Acarology, National Museum, Bloemfontein

Louise Coetzee, MSc

Department of Biostatistics, Faculty of Health Sciences, University of the Free State Gina Joubert, BA, MSc

Corresponding author: W Sinclair (sinclaiw@fshealth.gov.za)
Relative humidity (RH) affects HDM reproduction and survival. ${ }^{7,8}$ Critical equilibrium humidity (CEH) for Dermatophagoides pteronyssinus is $73 \%$ at $25^{\circ} \mathrm{C}$, below which dehydration occurs. At 40 - 50\% RH, mites survive for only 8 11 days, too short for active proliferation. At very high $\mathrm{RH}$, $>85 \%$, mites also struggle to survive because moulds proliferate in these conditions and produce toxins that may be detrimental to the mites. ${ }^{8}$ Mites probably prefer a fluctuating environment, with periods of high $\mathrm{RH}$ to maintain water balance and low $\mathrm{RH}$ to minimise mould growth. ${ }^{9}$

Different mite species are found in different geographical areas. For instance, in the USA D. farinae prevails, while in Western Europe the most common species is D. pteronyssinus. ${ }^{10}$ Since sensitisation to different species is evident it is important to identify the exact species found in the environment, which should be correlated with the positive tests found in the patient for appropriate management. Many other genera and species of mites may also be present, and sensitisation to these has also been demonstrated. We studied the abovementioned two species of HDM because they are usually implicated in the pathogenesis of allergies.

The presence of mites and levels of infestation can be determined by counting the number of visible organisms in dust samples and by measuring the levels of mite allergens in dust extractions. D. pteronyssinus allergens are measured by testing for Der $\mathrm{p} 1$, while Der $\mathrm{f} 1$ denotes $D$. farinae.

Seasonal factors are suspected to influence the numbers and activity of these mites, ${ }^{11}$ which are more likely to proliferate during warm, humid periods, numbers declining during cold, dry winters. Allergen levels are not expected to follow these fluctuations to the same degree, but may be affected by household cleaning routines.

We aimed to demonstrate the presence or absence of these mites in Bloemfontein, determining their abundance, if present, and seasonal variation throughout a 1-year period in several 
households. Our initial plan to determine allergen levels in the dust samples was prevented by the prohibitive cost of these tests.

\section{Objectives}

Primary objective. To demonstrate the absence or presence of HDMs in Bloemfontein.

Secondary objectives. To determine the species of HDMs found in Bloemfontein, if present; outline seasonal fluctuations in HDM numbers, if present; correlate HDM numbers with the average seasonal temperature, relative humidity and rainfall; and determine indoor factors contributing to the proliferation of HDMs, if present.

\section{Material and methods}

\section{Study design}

This prospective, cohort study involved 10 houses of volunteers in Bloemfontein. A house had to be at least 10 years old and the mattresses and carpets to be tested had to have been in use for more than 6 months, as such dwellings are most likely to be infested by HDMs. ${ }^{12}$

Suitable houses of volunteers, mostly staff members of the Department of Dermatology, were chosen to represent different parts of Bloemfontein. The presence or absence of patients with atopic symptoms in these houses were not recorded or used as inclusion or exclusion criteria.

Informed consent was obtained from the owners of all the houses and the study was approved by the Ethics Committee of the Faculty of Health Sciences, University of the Free State, Bloemfontein, and registered with the National Clinical Trials Register.

\section{Collection and analysis of dust samples}

The dust was collected with a new 1800 -watt vacuum cleaner (AEG) by placing a fine filter in its suction pipe. The distal portion of the suction pipe was thoroughly cleaned between dust collections, to prevent cross-contamination between collection sites.

Dust was collected from: (i) a $2 \mathrm{~m}^{2}$ surface area of the mattress, from its top surface immediately under the bottom sheet, with suction lasting 2 minutes; ${ }^{13}$ (ii) the carpet area immediately in front of the bed, $2 \mathrm{~m}^{2}$, for 2 minutes; ${ }^{14}$ and (iii) the carpet area in front of the couch on which the inhabitants usually sat to watch television, $2 \mathrm{~m}^{2}$, for 2 minutes.

Collections in 5 of the houses were done monthly for 12 months, in the three sites mentioned, for mite counts and identification. In the other 5 houses the dust collections took place four times in 1 year, namely in the middle of January, April, July and October. Mite counts and identification were done on all samples.

The investigators did the collections. Dust was placed in sealed plastic freezer bags after collection. The areas studied were not to be vacuumed for at least 1 week before sampling, as frequent vacuuming significantly reduces mite levels. ${ }^{15,16}$ Carpets exposed to direct sunlight were not sampled, as such areas are usually free of HDMs. ${ }^{12}$
In the laboratory, the dust was weighed and separated into lots of about $100 \mathrm{~g}$, submerged in $80 \%$ ethanol and sorted out from where the mites were collected with a fine brush and placed on a microscope slide for identification and counting. ${ }^{17}$ Identification was done by an experienced acarologist (LC) according to standard pictorial keys. ${ }^{18}$ The results were expressed as the number of mites per $100 \mathrm{~g}$ of dust.

\section{Climatic factors}

Accurate statistics were kept daily of the following: maximum and minimum daily temperatures; relative humidity at 06h00, $12 \mathrm{~h} 00$ and $18 \mathrm{~h} 00$ each day; rainfall per 24-hour period; and barometric pressure at $06 \mathrm{~h} 00,12 \mathrm{~h} 00$ and $18 \mathrm{~h} 00$ each day. These figures were obtained from the website of the South African weather service, www.weathersa.co.za.

\section{Indoor factors that could influence mite proliferation}

Each home-owner filled in a questionnaire in which several questions were asked about conditions in the house: age of house; age of mattress tested; ages of carpets tested; number of inhabitants in house; number of people sleeping in bed tested; average number of times usually vacuumed; sun exposure of tested areas; heating methods; humidifiers used; air conditioning; electric blanket use; en-suite bathroom at tested bedroom; and presence of pets.

\section{Statistical analysis}

Numerical data were summarised by means, standard deviations, geometric means or percentiles as appropriate. Categorical data were summarised by frequencies and percentages.

\section{Results}

Five houses were completely free of HDMs throughout. In 2 houses a single individual mite (D. pteronyssinus) was found on one occasion each. Only 3 houses tested regularly positive for HDM.

Four other mite species were also found, comprising $11.73 \%$ of total mite numbers. One individual of Euroglyphus magnei (Cooreman) was found on one occasion (house 4), and Oribatida mites (20 individuals) were found in 6 houses, Prostigmata mites (28 individuals) in 7 houses, and Mesostigmata mites (16 individuals) in 6 houses. There was no correlation between the occurrence of HDMs and these mites, which were found almost exclusively on the carpets, with only two individual mites found in mattresses. No significant seasonal variation was found in their occurrence.

Of the HDMs found, $97.52 \%$ were D. farinae (Hughes), as would be expected in a dry climate. Mite numbers varied from $59 / 100 \mathrm{~g}$ to a maximum of $16265 / 100 \mathrm{~g}$.

The mite counts for the houses that tested positive were as follows:

House 2. Mite counts between 59 and 6 203/100 g were found, with the lowest number in December and the highest in August. No mites were found in January. Mites were only found on the bedroom carpet. 
House 4. Mite counts between 1644 and 16 265/100 g were found. December, January, February and March produced zero counts, but mites appeared in April and reached maximum counts in June, sustained at slightly lower numbers up to October. Mites were initially only found in the bedroom carpet, but later mostly in the mattress.

House 10. This house, sampled four times during the study period, consistently produced positive counts between 5813 and 13 363/100 g, with lower counts in January and April and higher levels in June and October.

Seasonal variation (Fig. 1) showed a rise in early winter, sustained into spring. Paradoxically, the numbers increased when climatic conditions were thought to be less favourable for mite proliferation.

Climate data showed that the $\mathrm{CEH}$ of $75 \%$ at $25^{\circ} \mathrm{C}$ was never reached. The outdoor conditions were therefore never suitable for HDM growth. From the literature we concluded that a hypothetical 'survivable day' for HDMs would have an average $\mathrm{RH}$ at or above $60 \%$ and median temperature at or above $20^{\circ} \mathrm{C}$. This would still not be suitable for HDM proliferation, merely for survival, and was achieved on only 37 days out of $366(10.12 \%)$. The spread of these 'survivable days' is shown in Fig. 2.

Paradoxically, the months with the highest number of these days (summer) had the lowest mite numbers in the houses that tested positive. The outdoor climate seemed totally unsuitable for HDMs and fluctuations in climate were irrelevant to HDM numbers indoors.

Because mites were found in significant numbers in only 3 houses, indoor 'climatic' factors had to be in play. The results of the questionnaires filled in by the owners showed that the 'positive' houses were significantly newer (12 years v. 39 years), more likely to have en-suite bathrooms at the tested bedrooms, and employed heating more often (both under-floor heating and oil heating), but all the other factors considered were essentially equal. This applied to the types of carpets, sunlight on the beds and carpets, ages of the mattresses and carpets, presence of pets, number of inhabitants and frequency of vacuuming.

Owing to the small number of houses in each group, none of the differences found were statistically significant, but under-floor heating, oil heating, air-conditioning and ensuite bathrooms showed differences that warrant further investigation. Unfortunately the amount of ventilation these rooms received was not assessed in the questionnaire.

\section{Discussion}

Our study confirms that HDMs occur in Bloemfontein, albeit in $30 \%$ of houses sampled. The outdoor climate during this period was totally unfavourable for the proliferation of HDMs, which we did not expect to find in the houses.

The numbers of mites found were lower than found in Spain $(79320 / 100 \mathrm{~g})^{19}$ but on par with Colombia (7 230 - 20 910/ $100 \mathrm{~g}) \cdot{ }^{20}$

The other 'non-HDM' mites found are not known to cause human disease. Oribatida (soil mites) occur mainly in the top $5 \mathrm{~cm}$ of soil. They live on dead plant material and fungi

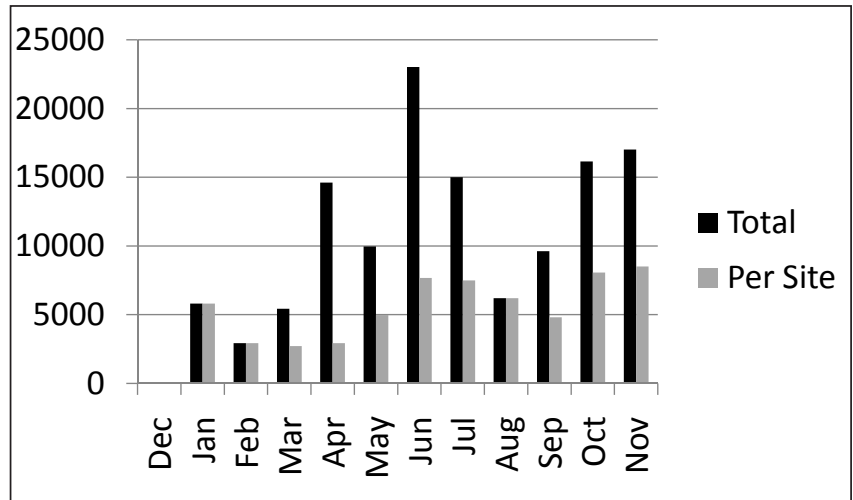

Fig. 1. Monthly total mite counts, also expressed as the average number per site where mites were found.

December 2007 - November 2008

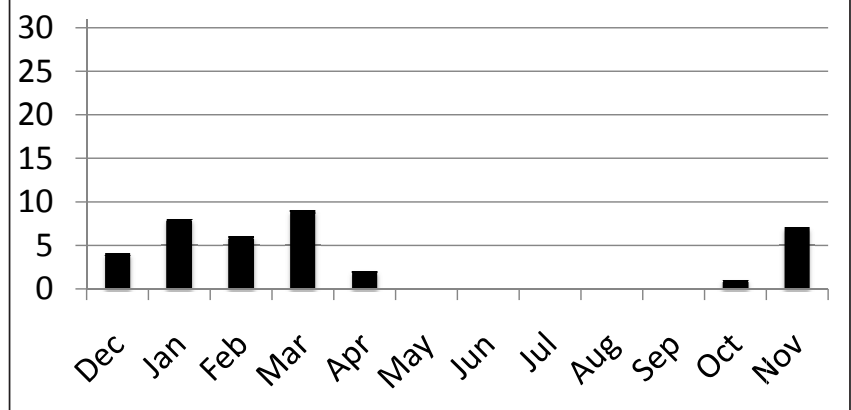

Fig. 2. 'Survivable days', with the numbers of suitable days per month on the vertical axis.

and have a decaying function. Their occurrence in houses would be coincidental, and they would probably have been carried in by shoes or pets as they do not appear to proliferate indoors. Prostigmata form a widely divergent group that can be terrestrial or aquatic and can exist as predators, as plant or fungus eaters and as parasites. Mesostigmata are also diverse; some are parasites and others predators, occurring in soil, dead plant material, compost, etc. ('detritus-based niches').

The dominant HDM species found, D. farinae, would be expected in a drier climate such as the Highveld of South Africa.

The fact that mites were found implies that microclimates created indoors by inhabitants of some houses make favourable conditions to allow HDMs to establish sustained populations. Heating of rooms may play a role, regardless of the method used. This would be expected, but without the necessary increased humidity, the higher temperatures alone would be insufficient to allow mite proliferation. None of the houses used humidifiers, but several rooms sampled had en-suite bathrooms, which would have a humidifying effect.

Ventilation (thereby equalising indoor and outdoor humidity and lowering indoor temperature) should be an important factor, and a shortcoming of this study is that an assessment of the amount of ventilation was not included in the questionnaire. There was a suggestion that inadequate ventilation could be at play. One house (No. 4) had no mites during summer but mites suddenly started to appear during April, which was sustained through winter and into the next summer. The owner had started renovations in a different part of the house during March, forcing them to keep all windows 


\section{Original ARTICLES}

closed in the tested bedroom, which had an en-suite bathroom. In another house that tested positive (No. 10), the modus operandi was that all the family members would take turns to use the en-suite bathroom of the main bedroom, after closing all the windows to keep the cold out during the winter months. The theory of inadequate ventilation would also explain the paradoxical increase in mite numbers during winter (Fig. 1). In very cold climates people tend to keep windows closed.

This may be an additional factor explaining the well-known phenomenon of worsening of atopic dermatitis during winter in central South Africa. This is usually attributed to the low humidity, warm brooding skin under many layers of clothing, use of woollen clothes, and excessive hot bathing to help combat the cold.

Ventilation should logically be the key factor in suppressing the proliferation of HDMs; if the climate indoors can be equated with the outdoor conditions as much as possible, it would theoretically not be possible for the mites to thrive indoors. This would be irrelevant at the coast or in tropical conditions, where the outdoor climate is also favourable for HDM proliferation. In a dry climate, however, increased ventilation throughout the year may be sufficient to rid houses of HDMs, and sophisticated and expensive methods such as are needed at the coast may not be necessary.

\section{Shortcomings of the study}

Too few houses were sampled owing to a shortage of manpower. The indoor climates were not formally monitored, as that would have placed a huge burden on the home-owners. The allergen levels in the dust samples were not measured, because this would have had to be done in the UK and the cost was prohibitive.

\section{Conclusion and recommendations}

HDMs occur in Bloemfontein, in about a third of houses, probably as a result of inadequate ventilation with or without en-suite bathrooms, especially during winter.

Mites found were mainly the 'American' HDM D. farinae. This holds implications for relevant allergy testing and desensitisation of patients, which in the drier areas of the country should be directed at this mite and not $D$. pteronyssinus.
We recommend that when individual patients with atopic symptoms show positive skin prick tests or RASTs for HDM hypersensitivity, the windows of bedrooms and living rooms be left open during the day as much as possible, even in winter. This is possible because winter daytime temperatures are usually pleasant. Some windows can then be closed at night to conserve heat indoors. This alone may be successful in removing HDMs as a trigger factor in atopic disease.

The authors wish to declare the absence of any conflict of interest.

References

1. Fernandez-Caldas E, Puerta L, Mercado D, Lockey RF, Caraballo LR. Mite allergens. Clin Allergy Imтипоl 2004; 18: 251-270.

2. Sporik R, Platts-Mills TA, Cogswell JJ. Exposure to house dust mite allergen of children admitted to hospital with asthma. Clin Exp Allergy 1993; 23(9): 740-746.

3. Squillace SP, Sporik RB, Rakes G, et al. Sensitization to house dust mite as a dominant risk factor for asthma among adolescents living in central Virginia. Multiple regression analysis of a population-based study. Am J Respir Crit Care Med 1997; 156(6): 1760-1764.

4. Spieksma F, Zuidema P, Leupen MJ. High altitude and house dust mites. BMJ 1971; 1: 82-84

5. South African Weather Service. http://www.weathersa.co.za (accessed 30 November 2008).

6. Cadman A, Prescott R, Potter PC. Year-round house dust mite levels on the highveld. S Afr Med J 1998; 88: 1580-1582.

7. Arlian LG. Water balance and humidity requirements of house dust mites. Experimental and Applied Acarology 1992; 16: 15-35.

8. Arlian LG, Confer PD, Rapp CM, Vyszenski-Moher DL. Population dynamics of the house dust mites Dermatophagoides farinae, D. pteronyssinus and Euroglyphus maynei (Acari: Pyroglyphidae) at specific relative humidities. J Med Entomol 1998; 35(1): 46-53.

9. Arlian LG, Neal JS, Bacon SW. Survival, fecundity and development of Dermatophagoides farinae at fluctuating relative humidity. J Med Entomol 1998; 35(6): 962-966.

10. Arlian LG, Neal JS, Vyszenski-Moher DL. Reducing relative humidity to control the house dust mite Dermatophagoides farinae. J Clin Immunol 1999; 104: 852-856.

11. Platt-Mills TAE, Chapman MD. Dust mites: Immunology, allergenic disease and environmental control. J Allergy Clin Immunol 1987; 80(6): 755-775.

12. Solarz K. Seasonal dynamics of house dust mite populations in bed/mattress dust from two dwellings in Sosnoweic (Upper Silesia, Poland): An attempt to assess exposure. Ann Agric Environ Med 1997; 4: 253-261.

13. Luczynska C, Sterne J, Bond J, Azima H, Burney P. Indoor factors associated with concentrations of house dust mite allergen, Der $\mathrm{p} 1$, in a random sample of houses in Norwich, UK. Clin Exp Allergy 1997; 28: 1201-1209.

14. Marks GB, Tovey ER, Peat JK, et al. Variability and repeatability of house dust mite allergen measurement: implications for study design and interpretation. Clin Exp Allergy 1995; 25: 1190-1197.

15. Loan R, Siebers R, Fitzharris $P$, Crane J. House dust mite allergen and cat allergen variability within carpeted living rooms in domestic dwellings. Indoor Air 2003; 13: 92-95.

16. Adilah N, Fitzharris P, Crane J, Siebers RW. The effect of frequent vacuum cleaning on the house dust mite allergen, Der p 1 in carpets: a pilot study. NZ Med J 1997; 110: 438-439.

17. Fain A, Hart BJ. A new, simple technique for extraction of mites, using the difference in density between ethanol and saturated $\mathrm{NaCl}$ (Preliminary note). Acarologia 1986; 27: 255-256.

18. Colloff MJ, Spieksma FThM. Pictorial keys for the identification of domestic mites. Clin Exp Allergy 1992; 22: 823-830.

19. Boquete $\mathrm{M}$, Iraola V, Fernàndez-Caldas $\mathrm{E}$, et al. House dust mite species and allergen levels in Galicia, Spain: A cross-sectional, multicenter, comparative study. J Invest Allergol Clin Immunol 2006; 16(3): 169-176

20. Fernandez-Caldas E, Puerta L, Mercado D, Lockey RF, Caraballo LR. Mite fauna, Der p 1, Der $\mathrm{f} 1$ and Blomia tropicalis allergen levels in a tropical environment. Clin Exp Allergy 1993, 23: 292-297.

Accepted 5 January 2010. 